\title{
Kerentanan Masyarakat Perkotaan terhadap Bahaya Banjir di Kelurahan Legok, Kecamatan Telanipura, Kota Jambi
}

\author{
Dian Adhietya Arif ${ }^{1}$, Djati Mardiatna ${ }^{2}$, dan Sri Rum Giyarsih ${ }^{3}$
}

Fakultas Geografi Universitas Gadjah Mada, Yogyakarta, Indonesia

Email Koresponden: srirum@ugm.ac.id

Diterima : Juni 2017 ; Direvisi : Juli 2017; Dipubikasikan: September 2017

๑ 2017 Fakultas Geografi UGM dan Ikatan Geograf Indonesia.

\begin{abstract}
Penelitian ini bertujuan untuk memetakan bencana banjir serta menganalisis kerentanan fisik dan sosial ekonomi masyarakat perkotaan terhadap bencana banjir di Kelurahan Legok, Kecamatan Telanipura, Kota Jambi. Penelitian ini menggunakan metode deskriptif kuantitatif. Data yang digunakan dalam penelitian ini terdiri atas data primer dan data sekunder. Data primer merupakan data yang diperoleh melalui observasi lapangan dan wawancara terstruktur dengan panduan kuesioner, sedangkan data sekunder merupakan data yang diperoleh dari dokumen-dokumen melalui instansi terkait yang berkompeten. Wawancara dilakukan terhadap 90 rumah tangga yang diambil dengan metode simple random sampling dari 476 populasi. Pengolahan dan analisis data dilakukan secara deskriptif kuantitatif dan dilengkapi dengan analisis spasial. Hasil penelitian menunjukkan bahwa berdasarkan hasil interpolasi kedalaman banjir tahun 2004 dapat diketahui bahwa sebagian besar wilayah penelitian terkena dampak banjir dengan kedalaman maksimum mencapai 3 meter di bagian timur wilayah penelitian. Fenomena ini disebabkan oleh beberapa faktor seperti kondisi topografi yang lebih rendah dibandingkan wilayah lainnya, terjadi penyempitan sungai dan kotornya saluran sungai sehingga menghambat air yang mengalir ke outlet utama. Penelitian ini juga menemukan bahwa tingkat kerentanan fisik tinggi ditemukan sebanyak 35 bangunan, kerentanan fisik sedang sebanyak 46 bangunan, dan kerentanan rendah sebanyak 9 bangunan. Tingkat kerentanan sedang hingga tinggi mendominasi wilayah penelitian karena jenis bangunan berupa bangunan non tembok. Temuan penelitian yang lain adalah kerentanan sosial ekonomi lebih tinggi ditemukan pada elemen tingkat pendidikan dengan sebagian besar tingkat berpendidikan rendah yaitu sekolah dasar (SD) (44,4\%) dan elemen penduduk rentan karena usia lanjut dan anak-anak sebanyak 30,4\%.
\end{abstract}

Kata-kata kunci : Masyarakat Perkotaan, Kerentanan Fisik, Kerentanan Sosial Ekonomi, Bahaya Banjir

Abstract This research aimed to map flood hazard as well as to analyze the physical and socioeconomic vulnerability of the urban community to floods in Legok Sub-district, Telanipura District, Jambi City. It employed a quantitative descriptive method and used both primary and secondary data. The primary data were obtained from field observation and questionnaire-assisted structured interview, while the secondary data were acquired from documents published by relevant competent institutions. The interviews involved 90 households that were selected with simple random sampling from 476 population. Data processing and analysis were performed in a quantitative descriptive manner and complemented with spatial analysis. Based on the interpolation of flood depth in 2004, most of the research area was affected by floods with a maximum depth of $3 \mathrm{~m}$ in the east. Such impact was caused by several factors like lower topographic condition, river narrowing, as well as dirty and clogged tributaries that inhibited water flow to the main outlet. This research also found high, medium, and low physical vulnerability in 35, 46, and 9 buildings, respectively. The medium and high physical vulnerabilities were identified in most of the research area due to the predominance of non-walled buildings. Another research finding was a higher socioeconomic vulnerability among the low-educated people (i.e., elementary school, 44.4\%) and vulnerable groups (i.e., elderly and children, 30.4\%).

Keywords: Urban Community, Physical Vulnerability, Socioeconomic Vulnerability, Flood Hazard

\section{PENDAHULUAN}

Kelurahan Legok merupakan wilayah sempadan Sungai Batanghari yang sekaligus merupakan wilayah dataran aluvial. Wilayah dataran aluvial merupakan kawasan budidaya yang produktif di mana terdapat pemanfaatan lahan oleh manusia untuk permukiman, perdagangan, dan pertanian (Marfai, 2011; Duckers, 2015; Neale and Weir, 2015). Kondisi ini didorong oleh ketersediaan sumberdaya yang melimpah berupa kondisi tanah yang subur, ketersediaan air dan aksesibilitas yang memadai (Taylor and Peace, 2015; Ullah et al., 2015).
Namun demikian, wilayah dataran aluvial adalah wilayah yang rawan dan berpotensi untuk muncul bencana banjir. Kejadian bencana banjir menimbulkan dampaksosial ekonomi yang sangat besar bagi penduduk yang mengalaminya (Septriyadi and Hamhaber, 2013; Wesli et al., 2013; Zorn et al., 2015; Rachmawati and Budiarti, 2016). Sebagai contoh, pada tahun 2010 terjadi bencana banjir di Kelurahan Legok yang menggenangi sebanyak 662 rumah (Jambikota.go.id, 2015). Masalah yang ditimbulkan oleh banjir cukup besar yaitu terganggunya aktifitas sosial dan ekonomi 
akibat tergenangnya ruas jalan serta terganggunya kesehatan masyarakat.

Besarnya konsentrasi aktivitas manusia di wilayah ini harus diimbangi dengan tindakan mitigasi bencana guna mengurangi dampak yang ditimbulkan oleh banjir, sehingga lahan dapat dimanfaatkan secara berkelanjutan (Haryani, 2012; Ma'arif et al., 2014; Widianto and Damen, 2014). Dalam melaksanakan tindakan mitigasi bencana diperlukan informasi spasial berkaitan dengan bencana banjir (durasi, kedalaman, ekstensi) dan tingkat kerentanan fisik dan sosial.

Banjir adalah suatu peristiwa tingginya aliran sungai di mana air menggenangi wilayah dataran banjir. Bencana banjir diukur dengan probabilitas terjadinya kerusakan yang secara umum disebut sebagai risiko banjir, atau dampaknya terhadap masyarakat seperti korban jiwa atau kerusakan material masyarakat (Dewi, 2007). Bencana banjir merupakan ancaman bagi penduduk beserta aktivitasnya, dan risiko bencana banjir meningkat di banyak tempat disebabkan oleh intensifnya pembangunan pada wilayah dataran banjir (Sagala et al., 2012; Sakijege, 2013). Perubahan penggunaan lahan menjadi kawasan terbangun dapat meningkatkan risiko bencana banjir disebabkan oleh berubahnya karakteristik run off, dan jalur drainase bagi air (Cahyadi et al., 2011; Cahyadi dkk., 2012). Kondisi ini diperparah dengan terjadinya perubahan iklim di mana beberapa tempat mengalami perubahan frekuensi curah hujan (Sene, 2008; Dibyosaputro dkk., 2016).

Kejadian banjir pada umumnya terjadi pada kawasan dataran banjir, di mana wilayah ini berkembang sebagai wilayah perkotaan disebabkan oleh kebutuhan dan melimpahnya ketersediaan sumberdaya air untuk beragam tujuan. Laju urbanisasi yang tinggi mempercepat pembangunan infrastruktur untuk memenuhi kebutuhan penduduk kota. Perkembangan tersebut terus berlanjut meskipun aktivitas ini meningkatkan kerentanan bencana jika aktivitas berlangsung melebihi kapasitas wilayah terhadap perubahan (Genovese, 2006).

Kerusakan yang disebabkan oleh banjir merupakan cerminan dari kurangnya kesiapan bencana. Sebagian besar alasan munculnya masalah ini adalah karena kurangnya penyediaan infrastruktur serta kurang matangnya perencanaan dalam pengelolaan wilayah terdampak bencana. Elemen berisiko adalah tingkat kemungkinan suatu elemen untuk mengalami dampak bahaya. Elemen-elemen tersebut dapat berupa penduduk, bangunan, pelayanan publik, kegiatan ekonomi, dan infrastruktur (Nott, 2006 dalam Wigati, 2008; Marfai and King, 2008; Marfai et al., 2008)

Kerentanan adalah tingkat kerugian yang dapat dialami oleh elemen terdampak dengan tingkat keparahan tertentu yang dihasilkan oleh bahaya tertentu. Tingkat kerentanan masyarakat terhadap dampak bencana ditentukan oleh beberapa kondisi yaitu kondisi fisik, sosial, ekonomi, lingkungan, dan proses yang berlangsung di dalamnya. Menurut Cutter (1996) dalam Dewi (2007) kerentanan suatu daerah terhadap bencana berkaitan dengan kondisi geografisnya (Gambar 1). Potensi bencana suatu wilayah akan berkurang ataupun meningkat bergantung pada kondisi fisik wilayah serta struktur sosial penduduk di wilayah tersebut. Struktur sosial yang dimaksud yaitu berkaitan dengan kearifan lokal dalam menghadapi bencana, respon penduduk dalam mengatasi, pemulihan, dan beradaptasi terhadap bencana.

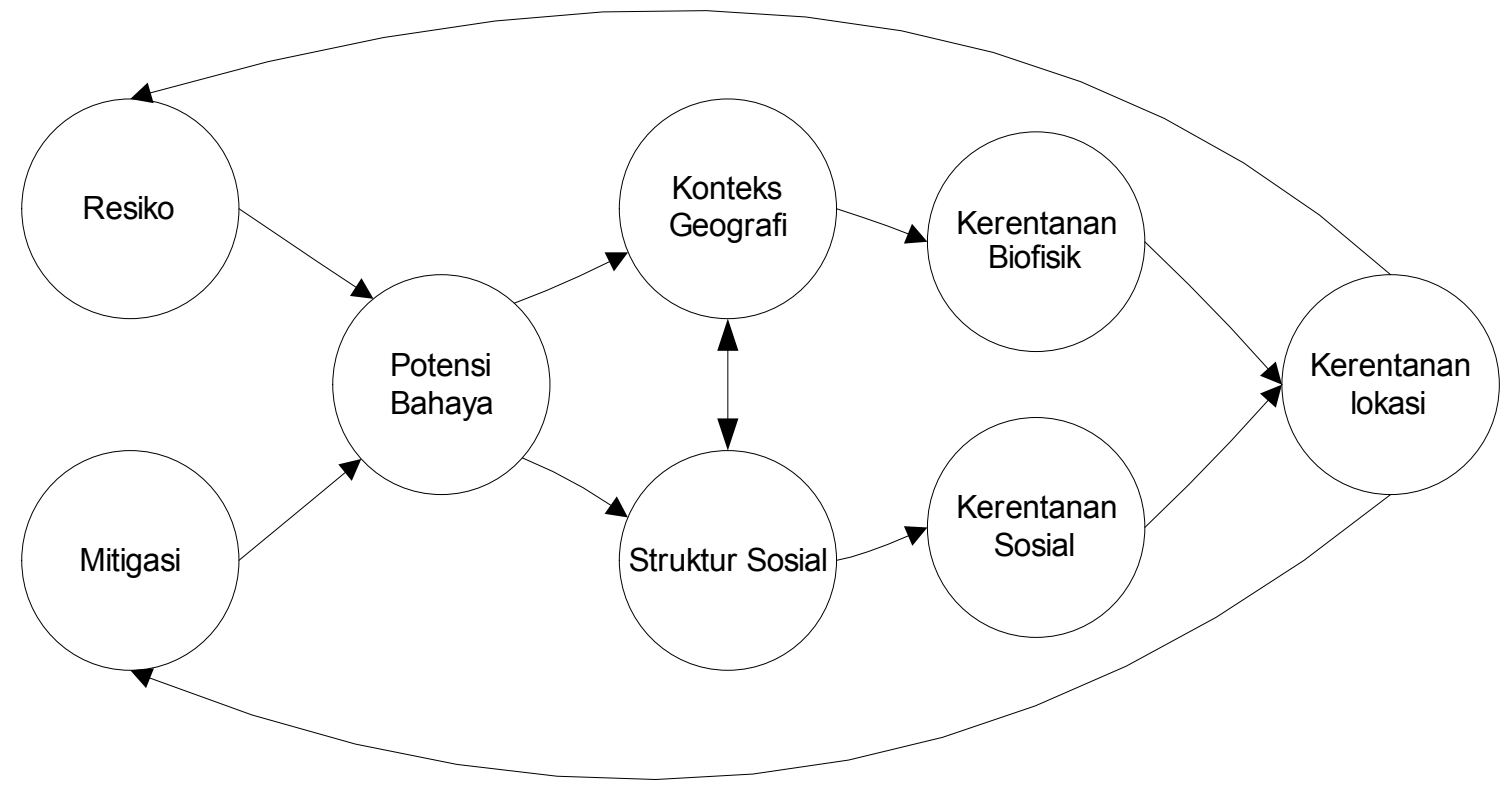

Gambar 1. Model Kerentanan Menurut Cutter (1996) dalam Dewi (2007) 
Pemetaan terhadap bencana banjr sebagai upaya mitigasi bencana sangat penting untuk dilakukan. Hal ini karena upaya penanganan terhadap kejadian banjir dapat lebih baik jika ditambahkan dengan kajian tingkat kerentanan fisik dan sosial pada wilayah terdampak bencana banjir. Dengan demikian maka, penelitian ini bertujuan untuk (1) memetakan bencana banjir di Kelurahan Legok, dan (2) menganalisis kerentanan fisik dan sosial ekonomi masyarakat perkotaan terhadap bencana banjir di Kelurahan Legok.

\section{METODE PENELITIAN}

Lokasi penelitian adalah Kelurahan Legok yang secara fisik morfologi maupun secara yuridis administratif termasuk wilayah perkotaan. Kelurahan Legok secara administrasi merupakan bagian dari Kecamatan Telanaipura, Kota Jambi (Gambar 2). Lokasi ini terletak pada koordinat UTM 341709 - 345409 mT dan 9824487 - $9822726 \mathrm{mU}$ zona 48S dan memiliki luas $3,51 \mathrm{~km}^{2}$. Kelurahan Legok berada di sempadan Sungai Batanghari yang merupakan sungai utama dalam Daerah Aliran Sungai (DAS) Batanghari Hilir. Pemilihan Kelurahan Legok sebagai wilayah penelitian berdasarkan pertimbangan bahwa wilayah ini sering mengalami kejadian banjir. Secara geomorfologi wilayah ini berada di sempadan sungai yang rentan terhadap bahaya banjir. Toponimi wilayah yang bernama Legok (ledok) menunjukkan bahwa wilayah ini merupakan cekungan, sehingga berpotensi menjadi pusat larian air dari wilayah di atasnya.

Penelitian ini menggunakan metode deskriptif kualitatif. Data yang digunakan dalam penelitian ini terdiri atas data primer dan data sekunder. Data primer merupakan data yang diperoleh melalui observasi lapangan dan wawancara terstruktur dengan panduan kuesioner. Sementara itu data sekunder merupakan data yang diperoleh dari dokumen-dokumen melalui instansi terkait yang berkompeten. Data yang digunakan dalam penelitian disajikan dalam Tabel 1.

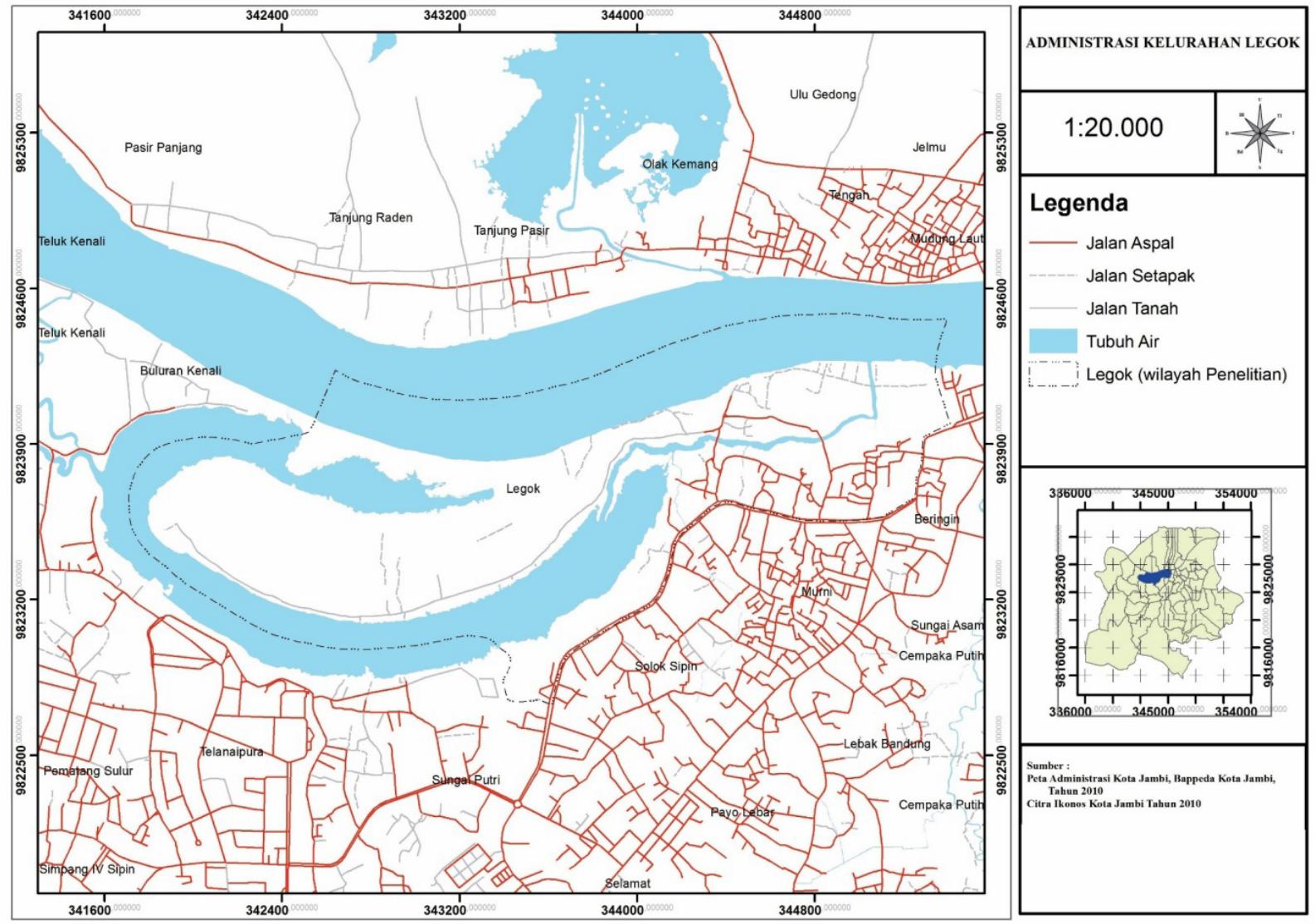

Gambar 2. Peta Administrasi Kelurahan Legok 
Tabel 1. Jenis Data yang Digunakan dalam Penelitian

\begin{tabular}{ll}
\hline \multicolumn{1}{c}{ Jenis data } & \multicolumn{1}{c}{ Sumber } \\
\hline DEM & Citra SRTM dan observasi lapangan \\
Penggunaan lahan & Citra ikonos tahun 2011 \\
Kondisi sosial ekonomi masyarakat & Hasil wawancara \\
Data hujan & Badan BMKG Jambi \\
Data kejadian banjir & Balai wilayah sungai VI PU Provinsi Jambi \\
Data sebaran banjir, durasi, dan kedalaman & Observasi lapangan dan wawancara \\
Tingkat ancaman elemen terdampak bencana & Observasi lapangan dan wawancara \\
Tingkat kerentanan fisik dan sosial & Observasi lapangan dan wawancara \\
\hline
\end{tabular}

Populasi dalam penelitian ini adalah seluruh rumah tangga yang menghuni bangunan yang ada di Kelurahan Legok (476 rumah tangga di 476 blok bangunan). Seluruh bangunan yang masuk sebagai populasi dikelompokkan dalam tiga golongan tipe struktur bangunan yaitu tipe bangunan tembok, bangunan semi tembok, dan bangunan non tembok. Pengambilan sampel ditetapkan berjumlah 90 rumah tangga di 90 blok bangunan dan sampel diambil dengan metode simple random sampling.

Pemetaan banjir dilakukan dengan memanfaatkan informasi spasial banjir oleh penduduk di wilayah penelitian. Data berupa kedalaman banjir, sebaran wilayah genangan, dan durasi banjir diperoleh dengan melakukan wawancara terstruktur terhadap masyarakat. Data kedalaman banjir yang disimbolkan sebagai data titik digunakan sebagai data dasar dalam interpolasi wilayah tergenang dengan memanfaatkan software ArcGIS 10.1. Hasil akhir berupa peta bencana banjir.

Penilaian terhadap kerentanan dilakukan terhadap kondisi fisik dan kondisi sosial ekonmi. Nilai kerentanan secara fisik diukur berdasarkan parameter berupa jenis bangunan, tinggi pondasi bangunan, kedalaman banjir, dan tingkat kerusakan bangunan. Kerusakan yang diamati pada penelitian ini adalah kerusakan pada dinding dan lantai bangunan. Sagala (2006) menyatakan bahwa dinding dan lantai pada suatu bangunan merupakan bagian yang mudah mengalami kerusakan saat banjir. Tingkat kerentanan dianalisis dengan memanfaatkan software ArcGIS 10.1., dan hasil pengolahan diklasifikasikan ke dalam tiga kelas kerentanan. Analisis nilai kerentanan sosial ekonomi dilakukan terhadap indikator kerentanan berupa penduduk terpapar dan kelompok rentan. Analisis ini dilakukan terhadap data hasil wawancara dengan variabel pendapatan penduduk, komposisi umur penduduk, dan komposisi jenis kelamin.

\section{HASIL DAN PEMBAHASAN}

\section{Pemetaan Wilayah Banjir}

Kedalaman banjir diklasifikasikan ke dalam tiga kelas yaitu rendah ( $0-1$ meter), sedang ( $1-2$ meter), dan tinggi ( $>2$ meter). Pembagian kelas kedalaman banjir didasarkan atas pengaruh yang ditimbulkan oleh banjir dan tindakan apa yang dilakukan oleh masyarakat. Kedalaman banjir yang rendah tidak terlalu membahayakan properti yang dimiliki penduduk, karena sebagian besar bangunan rumah berupa rumah panggung dengan tinggi tiang antara $1-2 \mathrm{~m}$. Penduduk dapat bertahan terhadap banjir dengan tingkat kedalaman rendah. Penduduk menyampaikan bahwa kedalaman banjir sedang hingga tinggi dapat mengganggu aktifitas baik dalam kegiatan perekonomian maupun sosial, sehingga penduduk harus mempersiapkan perahu sebagai sarana transportasi selama banjir.

Kecepatan aliran air pada saat banjir tidak terlalu cepat. Banjir di wilayah penelitian disebabkan oleh karena banjir kiriman dan hasil dari arus balik Sungai Batanghari yang masuk ke Danau Sipin. Aliran banjir dapat bergerak dengan bebas dan tidak tertahan oleh bangunan karena sebagian besar rumah penduduk berupa rumah panggung dengan pilar-pilar yang tinggi. Durasi banjir rata-rata adalah selama 4 minggu. Beberapa penduduk mengungkapkan bahwa wilayah mereka dapat tergenang hingga 12 minggu. Kondisi ini disebabkan oleh bangunan permukiman penduduk berada di wilayah yang berbatasan langsung dengan tubuh air atau berada di wilayah yang selalu tergenang oleh air sepanjang tahun.

Umur bangunan di wilayah penelitian lebih dari 10 tahun. Kondisi ini mengindikasikan bahwa kearifan lokal dalam menghadapi banjir telah berkembang dengan baik berdasarkan pengalaman-pengalaman penduduk dalam menghadapi situasi bencana banjir, sehingga mampu bertahan untuk menetap di wilayah tersebut. Umur bangunan juga berkontribusi terhadap keamanan penduduk dan ketahanan terhadap bahaya banjir. Hal ini bergantung kondisi bangunan itu sendiri dan jenis material yang digunakan.

Berdasarkan peta genangan banjir menunjukkan bahwa tidak semua wilayah penelitian mengalami banjir. Banjir tidak terjadi di bagian selatan dan tenggara wilayah penelitian disebabkan wilayah tersebut memiliki elevasi yang lebih tinggi dibanding bagian wilayah lainnya (Gambar 3). 


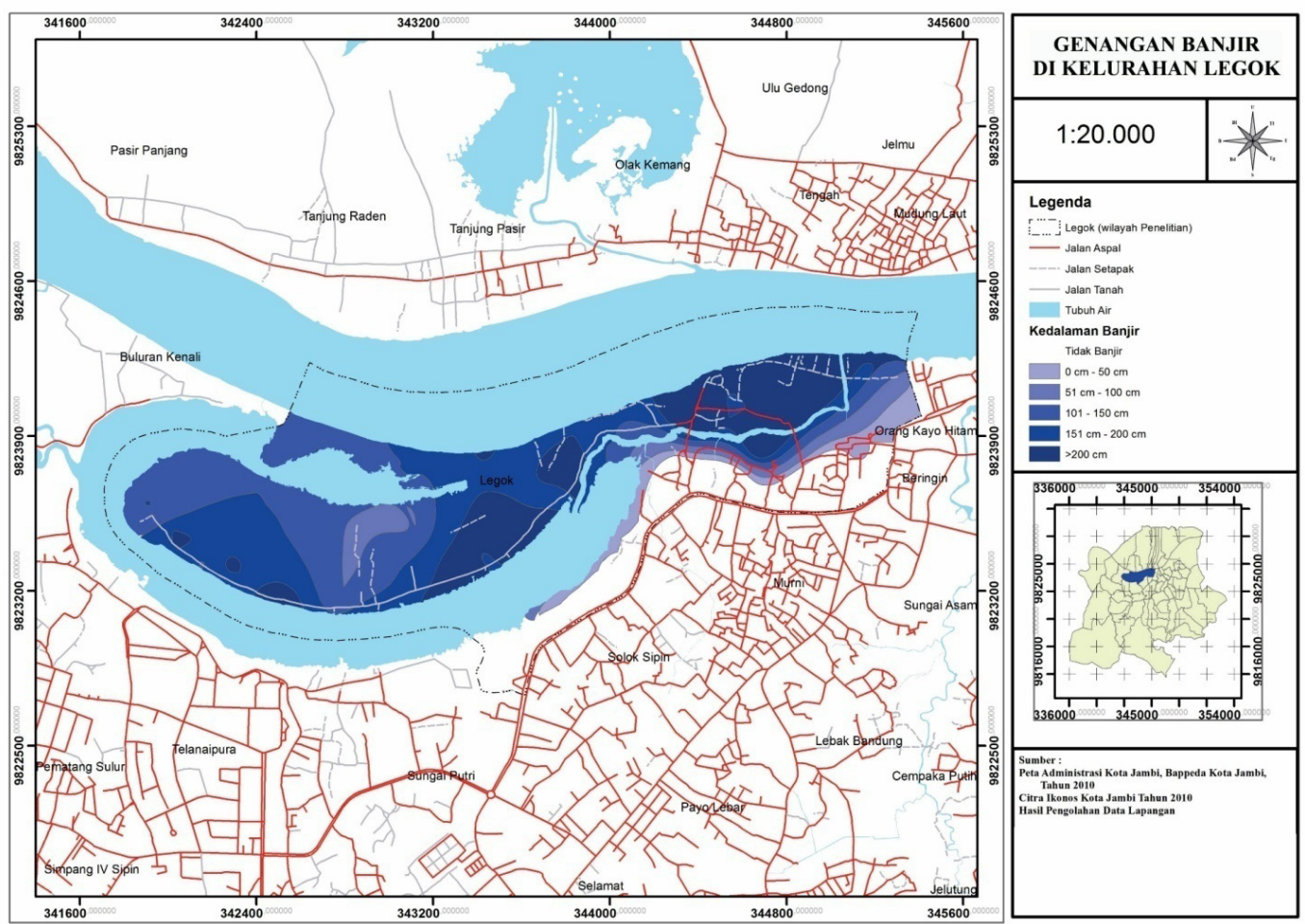

Gambar 3. Peta Genangan Banjir

\section{Kerentanan Fisik dan Sosial Ekonomi}

\section{Kerentanan Fisik}

Pemetaan kerentanan fisik dilakukan terhadap 90 sampel di wilayah penelitian. Jenis konstruksi/ material fisik bangunan merupakan salah satu faktor yang mempengaruhi mudahnya suatu bangunan mengalami kerusakan (Guarin, 2003). Jenis bangunan yang diteliti dalam penelitian ini adalah bangunan non tembok, semi tembok, dan tembok (Gambar 4). Jenis bangunan non-tembok adalah berupa kayu/papan. Jenis bangunan semi tembok merupakan campuran antara beton dengan kayu. Jenis bangunan tembok terbuat dari beton dengan kombinasi bahan yaitu batu bata, semen, dan pasir. Kerusakan yang diamati pada penelitian ini adalah kerusakan pada dinding dan lantai bangunan.

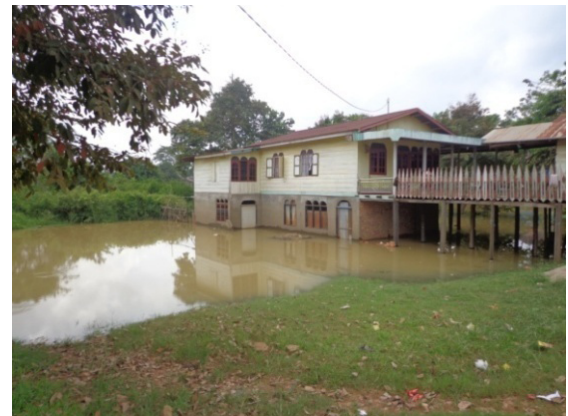

(a)

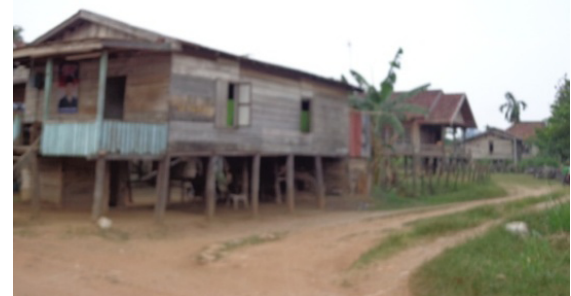

(b)

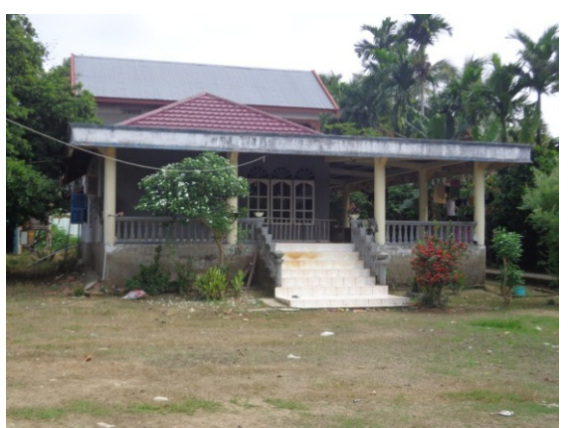

Gambar 4. Bangunan Non-Tembok, Semi Tembok, dan Tembok 
Tinggi pondasi bangunan merupakan salah satu variabel untuk menentukan kerentanan fisik. Tinggi pondasi bangunan rata-rata untuk bangunan non tembok adalah $135 \mathrm{~cm}$, bangunan semi tembok 127 $\mathrm{cm}$, dan bangunan tembok $72 \mathrm{~cm}$. Kedalaman rata-rata banjir di wilayah penelitian adalah $171 \mathrm{~cm}$. Data tinggi pondasi bangunan sangat beragam antara 0 hingga
$250 \mathrm{~cm}$. Pengukuran tinggi pondasi bangunan rumah panggung di lokasi penelitian diklasifikasikan ke dalam tiga kelas (Tabel 3). Hasil penelitian menunjukkan bahwa tingkat kekuatan bangunan untuk bertahan terhadap banjir untuk masing-masing kategori bangunan disajikan pada Tabel 4.

Tabel 3. Kelas Tinggi Pondasi Bangunan

\begin{tabular}{cccc}
\hline Kategori & Ketinggian Fondasi & Jumlah & $\%$ \\
\hline Rendah & $0-100 \mathrm{~cm}$ & 40 & 44,44 \\
Sedang & $101 \mathrm{~cm}-200 \mathrm{~cm}$ & 45 & 50,00 \\
Tinggi & $>200 \mathrm{~cm}$ & 5 & 5,56 \\
& Jumlah & 90 & 100,00 \\
\hline
\end{tabular}

Sumber: Pengolahan Data Primer Tahun 2016

Tabel 4. Kerentanan Jenis Bangunan

\begin{tabular}{cccc}
\hline No. & Jenis Bangunan & Kerentanan & $\%$ \\
\hline 1 & Non Tembok & Tinggi & 51,1 \\
2 & Semi Tembok & Sedang & 7,6 \\
3 & Tembok & Rendah & 41,3 \\
& & & 100,0 \\
\hline
\end{tabular}

Sumber: Hasil Analisis Data Tahun 2016

Kerentanan fisik diperoleh dengan menumpang susunkan peta jenis struktur bangunan dengan tinggi pondasi bangunan. Klasifikasi tingkat kerentanan fisik dilakukan dengan metode matriks berdasarkan aturan Badan Nasional Penanggulangan Bencana (BNPB). Kelas kerentanan fisik dibagi dalam tiga kelas yaitu kerentanan rendah, sedang dan tinggi. Matriks pengkelasan kerentanan fisik struktur bangunan dapat dilihat pada Tabel 5. Hasil tumpang susun antara peta jenis bangunan dan peta tinggi pondasi bangunan menghasilkan tingkat kerentanan struktur bangunan.

Tabel 5. Kelas Kerentanan Fisik Bangunan

\begin{tabular}{lllll}
\hline \multirow{2}{*}{\multicolumn{2}{l}{ KerentananFisik }} & \multicolumn{3}{c}{ Tinggi PondasiBangunan } \\
\cline { 2 - 5 } & Rendah & Rendah & Sedang & Tinggi \\
\hline \multirow{3}{*}{ JenisBangunan } & Sedang & Rendah & Rendah & Sedang \\
& Tinggi & Sedang & Sedang & Tinggi \\
& & & Tinggi & Tinggi \\
\hline
\end{tabular}

Berdasarkan Gambar 5 dapat dicermati bahwa sebaran kelas kerentanan tinggi terkonsentrasi di bagian timur laut wilayah penelitian, sedangkan kelas kerentanan sedang dan rendah tersebar merata di seluruh wilayah penelitian. Peta hasil tumpang susun menunjukkan bahwa kerentanan fisik di lokasi penelitian didominasi oleh kelas sedang (51,11\%), diikuti kelas tinggi (38,89\%), dan kelas rendah (10\%).
Sebaran kelas kerentanan tinggi terkonsentrasi di bagian timur laut wilayah penelitian, sedangkan kelas kerentanan sedang dan rendah tersebar merata di seluruh wilayah penelitian. Jenis bangunan di bagian timur laut umumya berupa bangunan non tembok dengan tinggi pondasi sedang $(101 \mathrm{~cm}-200 \mathrm{~cm})$, sehingga bangunan di wilayah ini lebih rentan terhadap banjir. 


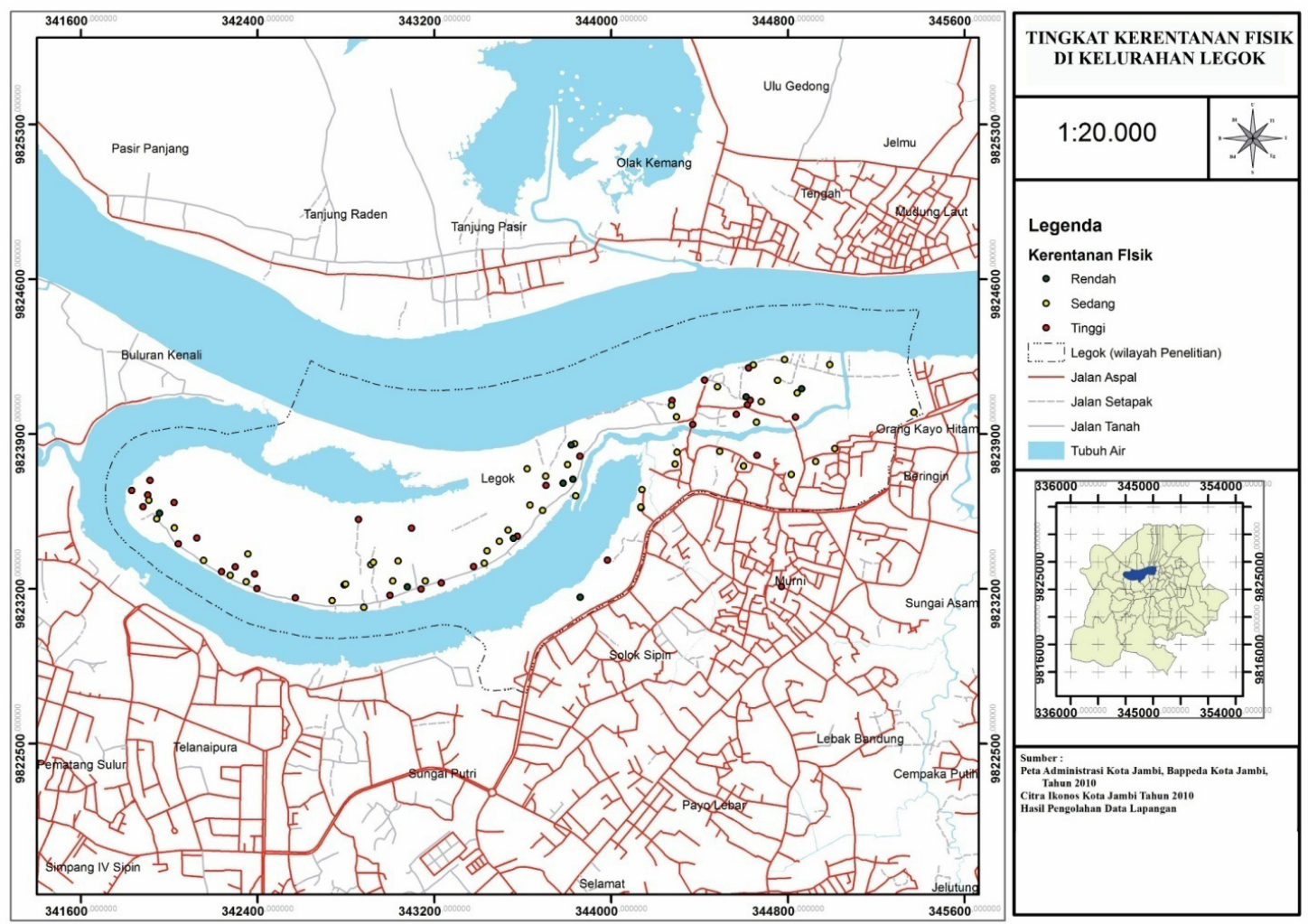

Gambar 5. Peta Kerentanan Fisik di Lokasi Penelitian

\section{Kerentanan Sosial Ekonomi}

Kerentanan sosial ekonomi berkaitan dengan kemampuan individu atau kelompok orang dalam menanggulangi, bertahan, dan pulih dari dampak kejadian bencana. Bencana akan terjadi ketika masyarakat menghadapi fenomena bahaya yang melebihi kapasitas masyarakat dalam menghadapi bahaya tersebut. Kondisi ini bermakna bahwa efek yang ditimbulkan suatu bencana dipengaruhi oleh tingkat kerentanan masyarakat terhadap bahaya (Twigg, 2011). Kondisi sosial ekonomi masyarakat merupakan salah satu aspek kerentanan yang perlu dikaji untuk mengetahui tingkat kemampuannya dalam menghadapi bencana. Kerentanan sosial dalam penelitian ini mencakup berbagai variabel yaitu pendapatan penduduk, jenis kelamin, pekerjaan, dan tingkat pendidikan.

Hasil penelitian menunjukkan bahwa komposisi umur didominasi oleh penduduk usia produktif (15-64 tahun) sejumlah 270 orang (69,59\%) diikuti oleh penduduk usia muda (0-14 tahun) sejumlah 84 orang $(21,65 \%)$ dan penduduk kelompok usia lanjut sejumlah 34 orang $(8,76 \%)$. Kondisi ini menunjukkan bahwa jumlah penduduk kelompok rentan lebih sedikit dibanding penduduk usia non rentan sehingga penanganan di saat bencana dapat lebih mudah. Faktor gender merupakan salah satu elemen yang berpengaruh terhadap munculnya kerugian akibat bencana. Penduduk perempuan lebih rentan terhadap bencana dibanding penduduk laki-laki. Hasil penelitian ini sejalan dengan temuan Twigg (2011) yang menyatakan bahwa data kematian akibat bencana di Bangladesh pada tahun 1991 menunjukkan bahwa angka kematian perempuan berumur sepuluh tahun, tiga kali lebih besar dibanding angka kematian laki-laki dalam umur yang sama.

Faktor umur juga merupakan salah satu elemen yang dapat dirugikan oleh kejadian bencana. Penduduk usia lanjut umumnya lebih rentan secara fisik disebabkan oleh faktor kesehatan jangka panjang baik itu masalah kesehatan pernapasan atau kardiovaskular, maupun masalah degradasi indra penglihatan maupun pendengaran (Twigg, 2011). Penduduk dengan usia lanjut, wanita, dan anak-anak merupakan kelompok rentan terhadap bencana sehingga perlu diprioritaskan untuk dievakuasi dari wilayah bencana. Hal ini harus didukung oleh rencana evakuasi yang baik agar proses evakuasi dapat berjalan dengan efektif dan efisien

Penelitian ini menemukan bahwa sebagian besar kepala rumah tangga di Kelurahan Legok berada di usia produktif dengan umur 30 - 40 tahun sebesar $31 \%, 40$ - 50 tahun sebesar 33\%, dan kepala rumah tangga berusia lanjut (> 50 tahun) sebesar 25\%, dan berusia muda (<30 tahun) sebesar 10\%. Kepala keluarga memiliki peranan penting dalam ketahanan menghadapi bencana. Pengelola rumah tangga adalah kepala keluarga dalam situasi apapun baik di waktu sebelum maupun di saat bencana. Kepala rumah tangga 
pria memiliki kelebihan dalam pembagian tugas dalam sebuah keluarga. Dalam rumah tangga di mana kepala keluarga adalah pria, posisi wanita adalah menunggu keputusan kepala keluarga mengenai tindakan apa yang akan diambil untuk menghadapi bencana.

Kepala keluarga wanita lebih rentan di mana mereka harus mempersiapkan segala sesuatu sendirian. Selain itu kepala keluarga wanita akan kesulitan untuk memperoleh bantuan dalam kondisi yang kacau saat terjadi bencana (Twigg, 2011). Hasil penelitian menunjukkan bahwa jumlah anggota keluarga dalam satu rumah bervariasi dengan anggota $4-6$ orang mendominasi dengan jumlah terbanyak, diikuti oleh kelompok keluarga dengan jumlah $>6$ orang, dan 0 - 3 orang. Besarnya jumlah anggota keluarga disebabkan oleh satu rumah ditempati oleh lebih dari satu kepala keluarga. Pasangan penduduk yang baru menikah masih menempati rumah orang tua dan hidup bersama. Besarnya jumlah anggota keluarga juga dapat bermanfaat ketika terjadi bencana, sebab anggota keluarga dapat menjadi tenaga kerja tambahan apabila pekerjaan utama tidak dapat memberikan penghasilan yang mencukupi.

Hasil penelitian yang lain adalah tingkat pendidikan penduduk di wilayah penelitian didominasi Sekolah Dasar (SD) sebanyak 44,44\%, diikuti oleh Sekolah Menengah Atas (SMA) sebanyak 34,44\%, Sekolah Menengah Pertama (SMP) sebanyak 18,89\% dan perguruan tinggi sebanyak 2,22\%. Kondisi ini menandakan bahwa sebesar $63,33 \%$ penduduk tidak memenuhi program pemerintah wajib belajar sembilan tahun. Tingkat pendidikan yang rendah menyebabkan penduduk tidak banyak memiliki pilihan pekerjaan yang dapat dilakukan. Kondisi ini akan berakibat pada sulitnya meningkatkan kualitas hidup penduduk, di mana penduduk tidak memiliki kecakapan yang baik untuk meningkatkan pendapatannya melalui pekerjaan yang baik pula.

Sebagian besar penduduk bermatapencaharian sebagai pegawai swasta (46\%) diikuti dengan wirausaha (33\%). Pekerjaan sebagian besar merupakan wiraswasta di mana penduduk bekerja pada perusahaan swasta baik di bidang jasa maupun perdagangan. Penduduk dengan pekerjaan tetap memiliki kerentanan yang rendah, karena memiliki penghasilan tetap yang dapat diandalkan untuk memenuhi pengeluaran pasca bencana.

Penduduk dengan pendapatan yang tinggi, tidak terlalu rentan dan terpengaruh oleh kejadian banjir. Penduduk dengan penghasilan tinggi akan memiliki tabungan yang mampu memberikan ketahanan finansial dalam menghadapi besarnya seluruh pengeluaran ekonomi di saat pra dan pasca kejadian banjir. Penduduk dengan pendapatan menengah merupakan penduduk dengan tingkat kerentanan sedang. Meskipun demikian kondisi penduduk ini masih lebih baik dibandingkan penduduk dengan pendapatan rendah.

\section{KESIMPULAN}

Berdasarkan hasil interpolasi kedalaman banjir tahun 2004 maka penelitian ini menyimpulkan bahwa sebagian besar wilayah penelitian terkena dampak banjir dengan kedalaman maksimum mencapai 3 meter di bagian timur wilayah penelitian. Hal ini disebabkan oleh beberapa hal yaitu kondisi topografi yang lebih rendah dibandingkan wilayah lainnya, terjadi penyempitan sungai dan kotornya saluran sungai, sehingga menghambat air untuk tersalurkan ke outlet utama. Berdasarkan analisis kerentanan fisik, maka penelitian ini menyimpulkan bahwa tingkat kerentanan fisik tinggi ditemukan sebanyak 35 bangunan, kerentanan fisik sedang sebanyak 46 bangunan, dan kerentanan rendah sebanyak 9 bangunan. Tingkat kerentanan sedang hingga tinggi mendominasi wilayah penelitian karena jenis bangunan berupa bangunan non tembok. Kerentanan sosial ekonomi lebih tinggi ditemukan pada elemen tingkat pendidikan dengan sebagian besar tingkat pedidikan rendah yaitu SD $(44,4 \%)$ dan elemen penduduk rentan karena usia lanjut dan anak-anak sebanyak $30,4 \%$.

\section{UCAPAN TERIMA KASIH}

Penulis menyampaikan ucapan terima kasih yang tak terhingga kepada Prof. Dr. rer.nat. Muh Aris Marfai, S.Si., M.Sc. dan Dr. Estuning Tyas Wulan Mei, S.Si., M.Sc. dari Fakultas Geografi Universitas Gadjah Mada yang telah berkenan untuk memberikan masukan yang sangat berarti demi kesempurnaan paper ini.

\section{DAFTAR PUSTAKA}

Cahyadi, A., Priadmodjo, A. \& Yananto, A. (2011). Criticizing The Conventional Paradigm of Urban Drainage. Proceeding The $3 \mathrm{rd}$ International Graduated Student Conference on Indonesia. Yogyakarta: Sekolah Pascasarjana Universitas Gadjah Mada.

Cahyadi, A., Yananto, A., Wijaya, M.S., \& Nugraha, H. (2012). Analisis Perubahan Penggunaan Lahan Terhadap Retensi Potensial Air oleh Tanah pada Kejadian Hujan Sesaat (Studi Kasus Perubahan Penggunaan Lahan di DAS Garang Jawa Tengah). Prosiding Seminar Nasional Informatika. Yogyakarta: Jurusan Informatika, UPN "Veteran" Yogyakarta.

Dewi, A. (2007). Community Based Analysis of Coping With Urban Flooding : a Case Study in Semarang, Indonesia. ITC, International Institute for GeoInformation Science, MSc Thesis, Enschede, The Netherland.

Dibyosaputro, S., Cahyadi, A., Nugraha, H. \& Suprayogi, S. (2016). Estimasi Dampak Perubahan Iklim Terhadap Kerawanan Banjir Lahar di Magelang, Jawa Tengah. Prosiding Seminar Nasional Geografi 
UMS2016. Surakarta:Universitas Muhammadiyah Surakarta.

Duckers, M., Frerks. G. \& Birkmann, J. (2015). Exploring the Plexus of Context and Consequences : An Empirical Test of A Theory of Disaster Vulnerability. International Journal of Disaster Risk Reduction, 13, 85-95.

Genovese, E. (2006). A Methodological Approach to Land Use-Based Flood Damage Assessment in Urban Areas: Prague Case Study. Institute for Environtmental Study

Haryani. 2012. Model Mitigasi Bencana di Wilayah Pesisir Dengan Pemberdayaan Masyarakat. Tata Loka, 14(3), 201-212.

Ma’arif, S., Damayanti, F., Suryanti, E.D., \& Wicaksono. A.P. (2014). Initiation of Desa Tangguh Bencana Through Stimulus-Response Method. Indonesian Journal of Geography, 44(2), 173-182

Marfai, M.A., \& King, L. (2008). Potential Vulnerability Implication of Coastal Inundation Due to Sea Level Rise for The Coastal Zone of Semarang City, Indonesia. Environmental Geology, 54, 1.2351.245 .

Marfai, M.A., L. King, L., Sartohadi, J., Sudrajat, Budiani, S.R. \& Yulianto, F. (2008). The Impact of Tidal Flooding on a Coastal Community in Semarang, Indonesia. Environmentalist, 28, 237-248.

Marfai, M.A. (2011). The Hazard of Coastal Erosion in Central Java Indonesia: An Overview. Geografia Online (3): 1-9.

Neale, T. \& Weir, J.K. (2015). Navigating Scientific Uncertainty in Wildfire and Flood Risk Mitigation : A Qualitative Review. International Journal of Disaster Risk Reduction 13: 255-267.

Rachmawati, R. \& Budiarti, C.V. (2016). Use of Space the Need For Planning in the Disaster-Prone Area of Code River, Yogyakarta, Indonesia. Indonesian Journal of Geography, 48 (2), 178-190.

Sagala, S., Pratama, A.A. Argo, T.A. \& Asirin. (2012). Peran Remitan Tenaga Kerja Indonesia Terhadap Potensi Pengurangan Risiko Bencana Banjir di Wilayah Perkotaan Indramayu. Tata Loka, 14(1), 37-51.

Sakijege, T. (2013). Managing Flood Risks : Lessons From Keko Machungwa Informal Settlement in Dares Salaam, Tanzania. Indonesian Journal of Geography, 45(1),1-14.

Sene, K. (2008). Flood Warning, Forecasting, and Emergency Responce. Springer.

Septriadi, R. \& Hamhaber, J. (2013). Hazard Assesment to Tidal Flood Inundation (Case Study : Tegal Municipality). Indonesian Journal of Geography, 45(1), 24-37.
Taylor, H. \& Peace, R.. (2015). Children and Cultural Influence in A Natural Disaster, Flood Response in Surakarta, Indonesia. International Journal of Disaster Risk Reduction, 13, 76-84.

Twigg, J. (2011). Disaster Risk Reduction, Mitigation and Preparedness in Development and Emergency Programming. London: ODI.

Ullah, R., Shivakoti, G.P. \& Ali, G. (2015). Factors Affecting Farmers'Risk Attitude and Risk Perception : The Case of Khyber Pakhtunkhwa, Pakistan. International Journal of Disaster Risk Reduction, 13, 151-157.

Wesli, Sirojuzilam, Matondang, A.R., Lubis, S. (2013). The Effect of Land Use and Community Participation on Flood Control at North Aceh District. Indonesian Journal of Geography 45, (2), 171-186.

Widianto, A. \& Damen, M. (2014). Determination on Coastal Belt in the Disaster Prone Area : A Case Study in the Coastal Area of Bantul Regency, Yogyakarta, Indonesia. Indonesian Journal of Geography, 46(2), 125-137.

Wigati, M. (2008). Improving Flood Hazard and Vulnerability Assessment Based on Social Assessment In Bogowonto River. MSc Thesis. Enschede, The Netherland: ITC, International Institute for Geo-Information Science.

Zorn, C., Asaad \& Shamseldin Y. (2015). Post-Disaster Infrastructure Restoration : A Comparison of Events For Future Planning. International Journal of Disaster Risk Reduction, 13, 158-166.

http:// www. Jambikota.go.id/id/index. php?option $=$ com content $\&$ task $=$ view $\&$ id $=596 \&$ itemid $=146$ 